\title{
COORDINATION OF PARTICIPANTS IN POOL MARKET USING GAME THEORY TO ALLOCATE FIXED COST
}

\author{
Anuprita Sandeep Mishra ${ }^{1}$, Ganga Agnihotri ${ }^{2}$, N.P.Patidar ${ }^{3}$, Baseem Khan $^{4}$ \\ Dept. of Electrical Engg.in Maulana Azad National Institute of Technology Bhopal, \\ India.
}

\begin{abstract}
The work proposes allocation of fixed cost inside a pool market by implementing Shapley approach of cooperative game in two folds: 1) locational charge as per usage made and 2) remaining charge. Meanwhile the required characteristic function for Shapley has been constructed by proposing a new method - MVA utility factor method. All attained solutions mostly lie in the core of the game, hence fairest, acceptable and equitable allocations are found. Authors also promoted MVA utility factor method to implement solely on the large systems where it is not easy to apply Shapley approach. In support of it correlation coefficients have been deduced to show nearness of MVA utility factor method towards Shapley approach. Illustrations have been made for IEEE 6 bus system, IEEE 14 bus system and IEEE 30 bus system as pool market.
\end{abstract}

\section{KEYWORDS}

MVA Utility Factors, Cooperative game, Shapley Value, Characteristic value, Remaining Charges, correlation coefficient.

\section{NOMENCLATURE}

$\begin{array}{ll}\text { nline } & \text { Total number of Transmission lines } \\ \text { nbus } & \text { Total number of bus } \\ \text { RC } & \text { Remaining charges } \\ A C C_{l}^{t} & \text { Adapted circuit cost of line } l \text { at } t^{t h} \text { instant } \\ U C C_{l}^{t} & \text { Used circuit capacity at } t^{t h} \text { instant } \\ C C_{l}^{t} & \text { Levelized cost for each hour of } l^{t h} \text { line at } t^{t h} \text { instant i.e embedded cost } \\ A E U D_{l k}^{t} & \text { Active extent of use by } k^{t h} \text { bus demand for } l^{t h} \text { line at } t^{t h} \text { instant. } \\ R E U D_{l k}^{t} & \text { Reactive extent of use by } k^{t h} \text { bus demand for } l^{t h} \text { line at } t^{t h} \text { instant } \\ P_{d k}^{t} & \text { Active demand on } k^{t h} \text { bus at } t^{t h} \text { instant } \\ Q_{d k}^{t} & \text { Reactive demand on } k^{t h} \text { bus at } t^{t h} \text { instant } \\ M V A P U F_{l d k}^{t} & \text { MVA utility active factor of } l^{t h} \text { line wrt } k^{t h} \text { bus demand at } t^{t h} \text { instant } \\ M V A Q U F_{l d k}^{t} & \text { MVA utility reactive factor of } l^{t h} \text { line wrt } k^{t h} \text { bus demand att } t^{t h} \text { instant } \\ M V A_{l}^{t} & \text { Absolute MVA flow in } l^{t h} \text { line at } t^{t h} \text { instant }\end{array}$




$\begin{array}{ll}P U B C P_{d k}^{t} & \begin{array}{l}\text { Partial recovery usage based charges for active demand on } k^{t h} \text { bus at } t^{t h} \text { instant } \\ P U B C Q_{d k}^{t}\end{array} \\ & \begin{array}{l}\text { Partial recovery usage based charges for reactive demand on } k^{t h} \text { bus at } \\ t^{t h} \text { instant }\end{array} \\ F U B C P_{d k}^{t} & \begin{array}{l}\text { Full recovery usage based charges for active demand on } k^{t h} \text { bus at } \\ t^{t h} \text { instant }\end{array} \\ F U B C Q_{d k}^{t} & \begin{array}{l}\text { Full recovery usage based charges for reactive demand on } k^{t h} \text { bus at } \\ t^{t h} \text { instant }\end{array} \\ \text { MVAUF } & \text { MVA utility factor }\end{array}$

(Same notation followed for generator with $\mathrm{g} / \mathrm{G}$ instead of $\mathrm{d} / \mathrm{D}$ )

\section{INTRODUCTION}

WORLDWIDE emergence of independent power producers in electrical industry has brought transmission pricing into a center of attention [1]. As action of one agent creates impact on other participant, thus fair cost allocation becomes difficult to investigate [2]. Many proposals of cost allocations embodied actual operation of transmission system. In which usage quantification for transmission lines are calculated either by tracing methods [3,4] or marginal participation (MP) [5] or distribution factors [6] or equivalent bilateral exchange method [7] or Z-bus method [8, 9] or cooperative game theory $[10,11,12]$. Out of all cooperative game is considered to be fairest for cost allocation.

Todays open access is a relatively recent concept of cooperation, so better represented as a cooperative game with loads and generators in the game [15]. Cooperative game takes into account the economies of scale, suggests reasonable allocations that may be economically efficient and offers fairest solution. In 1996, Tsukamoto and Iyoda [17], introduced the concept of cooperative game theory for fixed cost allocation. Similarly, Tan and Lie [18] in 2002 suggested that allocation using SV would be fair and desirable to impartial observers. Stamtsis and Erlich in 2004 [12] analyzed the cost allocation problem and realized SV is preferable when it is in the core of the game. Gan et al. in 2005 [20] introduced a game model in pool-based electricity markets. Junqueira et al. [21, 22] proposed a method based on Aumann-Shapley approach. In 2008 Bhakar et al. [23] allocated the network costs based on Nucleolus and SV. Next in 2010 [15] he described probabilistic values for game using SV.

In this work, Shapley value (SV) approach is used as it is a simple method [25], performs uniform cost allocation [26], overcomes the drawbacks of conventionally used methods and reflects the marginal contribution of a user to the aggregate system savings [1]. Here Shapley has been implemented in a pool market in two folds: 1) to allocate locational charges based on usage and 2) to allocate remaining charges so that problem of cross-subsidization of postage stamp method can be suppressed [24]. Meanwhile characteristic values of game have been constructed by proposing a new method - MVA Utility Factor method. It is an upgradation of Amp-Mile method $[2,29]$ based on MP and can be used separately for cost allocation.

In this work two comparisons have been revealed. First, MVA utility factor method is equivalent to Shapley approach. The closeness towards shapley have been deduced by corelation coefficients. Second, a comparison achieved through characteristic values constructed by tracing flow and MP, then cost allocations are evaluated, revealing that MP is more acceptable.

Rest of the paper is organized as follows: section 2 presents introduction of Shapley approach of 
cooperative game and formulation of proposed MVA Utility Factor method. Section 3 deals with results on IEEE 6 bus [14], IEEE 14 bus [1] and IEEE 30 bus [16] systems and established different comparision. Section 4 furnishes conclusion.

\section{Fixed Cost Allocation Game}

\subsection{Terminology of Game Theory and SV}

A cost allocation cooperative game is given by a couple $(N, v)$. Let $N=\{1,2,3, \ldots \ldots n\}$ the set of all participants (here loads and generators) in a game, $n$ corresponds to $|N|$. In a coalition $S$ players coordinate together to game, $S \subset N$. Result of the game or allocated cost is a pay-off vector $=\left\{x_{1}, x_{2}, x_{3}, \ldots . x_{n}\right\}$, where $x_{i}$ is the cost allocation to agent $i$ (generator or load). The following three conditions, namely: individual, group and global rationalities need to be satisfied to achieve optimal and fair allocation to all the players [10].

$x(i) \leq v(i) ; \quad i \in N$,

$x(S) \leq v(S) ; \quad S \subset N$

$x(N)=v(N)$;

With $x(S)=\sum_{i \in S} x(i)$;

Where characteristic value $v(S)$ gives the maximum cost incurred by the coalition $S$ by coordination between its members, irrespective of what other players and coalitions do [19]. There is no unique way of characterizing the cost of coalition, i.e. $v(S)$.

If (1), (2) and (3) are fulfilled then solution lies in the core of the game. Global rationality assumes that assignment of costs of the game to all the players must be identical to the total costs to be covered, known as break-even condition or Pareto-optimum [23]. Sometimes if SV does not belong to core, can also be acceptable [12] based on the network topology, number of players and their transaction patterns. In this work authors suggested acceptable payoffs (cost allocations) could be in the vicinity of core and SV can be a negative, justified due to existence of counter flows.

Depending on the order of entry of each player, net contribution to the grand coalition is obtained. The sum of each of such part gives SV. The SV denoted by $x(i)$ for a player $i$, is as below:

$x(i)=\sum_{s, i \in S} \frac{(|S|-1) !(|N|-|S|) !}{|N| !}[v(S)-v(S-\{i\})]$

\subsection{Characteristic Value: Formulation of MVA Utility Factor Method}

Proposed MVA Utility Factor method re-evaluated Amp-Mile method [2,29] with MP and presents efficient way for full recovery. In this method, impact of individual participant on the system is attributed through MVA flow. Proposed method is advantageous than Amp-Mile method as no question arises in relation to current limits since MVA flows can be increased under specified constraints of power network. 


\subsubsection{MVA utility factors:}

Authors have evaluated MVA utility factors by allowing small perturbations of $P_{d}, P_{g}$ and $Q_{d}$ at different buses. These are defined as

$M V A P U F_{l d k}^{t}=\partial M V A_{l} / \partial P_{d k}$

$M V A P U F_{l g k}^{t}=\partial M V A_{l} / \partial P_{g k}$

$M V A Q U F_{l d k}^{t}=\partial M V A_{l} / \partial Q_{d k}$

$M V A Q U F_{l g k}^{t}=0$

These inherently attributes the effect of slack bus power. Here use of AC load flow causes nonavailability of utility factors of lines for generator buses wrt Q generation, as these buses are self regulating the $\mathrm{Q}$. Nevertheless this portion of pricing can be considered separately by reactive power ancillary services [27].

\subsubsection{Formulation of line flows:}

Mathematically, the flow of a line using utility factor (UF) is

$M V A_{l}^{t}=\sum_{k=1}^{n b u s}\left\{M V A P U F_{l d k}^{t} \times P_{d k}^{t}+M V A P U F_{l g k}^{t} \times P_{g k}^{t}+M V A Q U F_{l d k}^{t} \times Q_{d k}^{t}\right\}$

This line flow would not be the actual flow in the circuit. To find authentic flow, reconciliation is needed.

\subsubsection{Extent of use:}

UFs can be employed for the evaluation of extent of use (EU) of a line by each participant and can be represented as:

$$
\begin{aligned}
& A E U D_{l k}^{t}=M V A P U F_{l d k}^{t} \times P_{d k}^{t} / M V A_{l}^{t} \\
& A E U G_{l k}^{t}=M V A P U F_{l g k}^{t} \times P_{g k}^{t} / M V A_{l}^{t} \\
& R E U D_{l k}^{t}=M V A Q U F_{l d k}^{t} \times Q_{d k}^{t} / M V A_{l}^{t} \\
& R E U G_{l k}^{t}=0
\end{aligned}
$$

Sum of all the EUs due to all participants is unity even though system is not fully loaded. This feature of the methodology is utilized to develop two types of allocation models; Partial recovery model (PRM) and Full recovery model (FRM). Implementation of either of these models depends on the transmission system.

\subsubsection{Partial recovery model}

Two types of charges are allocated

i) Partial Usage Based Charge (PUBC): Thses are allocated as per actual usage of the network.

ii) Remaining Charge (RC): This portion of allocation reflects charge to recover the cost of the unused network capacity. It is revealing security facet of the power system and has to be imposed on all participants. Expressions of PUBC and RC are:

$P U B C P_{d k}^{t}=\sum_{l=1}^{\text {nline }} A E U D_{l k}^{t} \times A C C_{l}^{t}$ 
Electrical and Electronics Engineering: An International Journal (ELELIJ) Vol 3, No 2, May 2014

$P U B C P_{g k}^{t}=\sum_{l=1}^{\text {nline }} A E U G_{l k}^{t} \times A C C_{l}^{t}$
$P U B C Q_{d k}^{t}=\sum_{l=1}^{\text {nline }} R E U D_{l k}^{t} \times A C C_{l}^{t}$
$P U B C Q_{g k}^{t}=0$
$P U B C_{k}^{t}=P U B C P_{d k}^{t}+P U B C P_{g k}^{t}+P U B C Q_{d k}^{t}$

Let $C C_{l}^{t}$ is levelized hourly cost of $l^{\text {th }}$ circuit which is constant and annual circuit cost will be $C C_{l}^{t} \times 8760$. Thus embedded cost of the circuit is either levelized hourly cost or annual circuit cost. Whereas adapted circuit cost $A C C_{l}^{t}$ is

$A C C_{l}^{t}=U C C_{l}^{t} \times C C_{l}^{t}$

Where $U C C_{l}^{t}$ is the used circuit capacity of line $l$ for time $t$ and defined by

$U C C_{l}^{t}=M V A_{l}^{t} / C A P_{l}$

And $C A P_{l}$ is the capacity of the line $l$. As $A C C_{l}^{t}$ depends on system usage hence variable, but

$\sum_{l=1}^{n l i n e} A C C_{l}^{t}=\sum_{k=1}^{n b u s} P U B C_{k}^{t}=\sum_{l=1}^{n l i n e} U C C_{l}^{t} \times C C_{l}^{t}$

Finally $R C$ is defined as

$R C^{t}=\sum_{l=1}^{n l i n e}\left[C C_{l}^{t}-A C C_{l}^{t}\right]$

In this work, authors followed PRM to construct characteristic value in SV approach. Thus characteristic value for shapley in terms of PRM is

$$
\begin{gathered}
v_{L}(S)=P U B C P_{d k}^{t}+P U B C P_{g k}^{t}+P U B C Q_{d k}^{t} \\
\text { e.g let } S=L 4, L 5 \text { (where } L 4 / 5 \text { is load on } 4^{\text {th }} / 5^{\text {th }} \text { bus) then } \\
v_{L}(L 4, L 5)=P U B C P_{d 4}^{t}+P U B C Q_{d 4}^{t}+P U B C Q_{d 5}^{t}+P U B C P_{d 5}^{t} \\
\text { And } v_{R}(S)=\sum_{l=1}^{\text {nline }}\left[C C_{l}^{t}\right]-v_{L}(L 4, L 5)
\end{gathered}
$$

\subsubsection{Full recovery model}

Full recovery model accomplishes total recovery of embedded cost by substituting $U C C_{l}^{t}$ unity in (14), consequently $A C C_{l}^{t}$ would be equal to $C C_{l}^{t}$ and accordingly revised form of (13) is given as:

$\sum_{k=1}^{n b u s} F U B C_{k}^{t}=\sum_{k=1}^{n b u s}\left(F U B C P_{d k}^{t}+F U B C P_{g k}^{t}+F U B C Q_{d k}^{t}\right)=\sum_{l=1}^{n l i n e} C C_{l}^{t}$

By following the same substitution for (16) $R C^{t}$ results in

$R C^{t}=\sum_{l=1}^{\text {nline }}\left[C C_{l}^{t}-C C_{l}^{t}\right]=0$ 
Eventually participants of transmission network have to pay for used capacity as well as unused capacity in proportion to their usage. This may be justified by the need of system meeting reliability, stability and security criteria for all the participants. The proposed technique is simple in application and not only provides price signals but $M V A U F$ 's constitute fundamental information in today's matured electricity market.

While applying cooperative game theory, FRM can not be used, as it generates characteristic values equal to circuit cost for all the coalitions. Finally in (5) SV turns to zero as explained below

$$
[v(S)-v(S-\{i\})]=\sum_{l=1}^{n l i n e} C C_{l}^{t}-\sum_{l=1}^{n l i n e} C C_{l}^{t}=0
$$

Therefore $\emptyset_{i}(v)=0$. Hence FRM can not be used to construct characteristic values.

\section{REULTS AND DISCUSSIONS}

Here allocated embedded cost is assumed proportional to the length of individual transmission lines in Rs./hr. Thus $C C_{l}^{t}$ is equal to the amount of the entire circuit length. The work follows the ratio for global cost allocation between generators and loads as 23\%:77\% in the pool market [16]. According to this trend the allocation of embedded cost has been splited in two parts: one $23 \%$ of embedded cost $\left(C C_{l}^{t}\right)$ to allocate among generators and another $77 \%$ of $C C_{l}^{t}$ to allocate among loads. Bilateral contracts are not allowed and the whole power is traded in a mandatory pool with the pool operator having a wide knowledge of the generator's data. Different IEEE systems have been considered as pool market place for realizing exclusively MVA Utility Factor method and then SV approach of cooperative game theory.

\subsection{IEEE 6 Bus System}

\subsubsection{Cost allocation by MVA Utility factor method:}

By following section 2.1 MVA Utility factor method has been implemented with its two different modes PRM and FRM. Results are shown in Table I Realization of proposed method demonstrated over other methods because it attains advantages like full recovery of EHV networks contrasting Amp-Mile, tackles reactive power unlike MW-Mile [13] and anticipates direction of reactive power distinct to MVA-Mile [14]. Authors suggest to allocate remaining charges by postage stamp method in PRM and in all other existing methods.

\subsubsection{Cost allocation by cooperative Game:}

The rationale behind forming a coalition in pool market using the sensitivity based characteristic function is counter flow.

\subsubsection{1 .Game among loads:}

The IEEE 6 bus system has been considered as pool market place and demands are given in the Table II. Game has been allowed among loads as they are the players in the pool market. It is assumed that the loads have no elasticity i.e. fully covered. If all the three loads are going to cooperate with each other, then the possible coalitions are 7 , including the single player coalition. 
The First three rows of Table III provide the stand alone cost of players and last row furnishes characteristic value (cost) corresponding to grand coalition using PRM of MVA utility factor method. SV for the three players are evaluated as shown in Table IV using (5). It describes the significance of game because if system would have been used by single player, then charge allocation will be more. Above all results obtained satisfy all the rationalities as depicted below.

i) Individual rationality, $x(i) \leq v(i)$;

$x(L 4) \leq v(L 4) \rightarrow 186.5689<213.8819$

$x(L 5) \leq v(L 5) \rightarrow 333.5845<355.7332$

$x(L 6) \leq v(L 6) \rightarrow 297.6696<362.0144$

ii) Group rationality $x(S) \leq v(S)$;

$x(L 4 L 5) \leq v(L 4 L 5)$

$x(L 4)+x(L 5) \leq v(L 4 L 5)$;

$186.5689+333.5845<547.4301$

$520.1534<547.4301$

iii) Global Rationality $x(N)=v(N)$;

$\sum_{i=L 4, L 5, L 6} x_{i}=v(L 4 L 5 L 6)=817.8229 R s . / h r$

Thus accomplishment of (2) along with (1) and (3) of game, proves that solution lies in the core. Hence, more likely to be accepted by the players. This encourages applicability of SV for fixed cost allocation.

\subsubsection{Game among generators:}

For the same IEEE 6 bus system as a pool market cooperative game has followed for generators. This was performed for $23 \%$ of entire embedded cost and the obtained payoffs remain in the core. Results are shown in Table V. Negative payoffs are justified in cost allocation problems as they are considered as incentives to agents.

\subsection{IEEE 14 Bus System}

A case with four players is considered for IEEE 14 bus system. Game can be performed for all loads but to explain the implication only four loads are being considered. These are the consumers at buses 4, 9, 12 and 14. Further game has been performed in two folds first for locational charges and second for remaining charges. Table VI establishes the information of two types of characteristic values i.e locational charge characteristic function - $v_{L}(S)$ and remaining charge characteristics function $-v_{R}(S)$. Then different coalitions are formed and shapley values are evaluated for locational charge as well as remaining charge.

\subsubsection{Game for locational charge allocation:}

Evaluated SV are shown in Table VII using (5). Comparision of standalone cost with SV confirms fulfillment of individual rationality (1). Fulfillment of global rationality (3) is demonstrated by observing characteristic value of grand coalition (last row) i.e 668.8631 in Table VI with total of SVs i.e 668.8631 in Table VII (last row). Next checking of group rationality (2) described below $x(S) \leq v(S)$;

i) $x(L 4 L 9) \leq v_{L}(L 4 L 9)$;

$x(L 4)+x(L 9) \leq v_{L}(L 4 L 9)$; 
$87.0039+325.8067<454.5853$

$412.8106<454.5853$

ii) $x(L 4 L 12) \leq v_{L}(L 4 L 12)$;

$x(L 4)+x(L 12) \leq v_{L}(L 4 L 12)$;

$87.0039+57.3997<154.7148$

$144.4036<154.7148$

iii) $x(L 4 L 9 L 12) \leq v_{L}(L 4 L 9 L 12)$;

$x(L 4)+x(L 9)+x(L 12) \leq v_{L}(L 4 L 9 L 12)$;

$87.0039+325.8067+57.3997<500.7899$

$470.2103<500.7899$

Thus, benefit of cooperation between the users of the transmission network is evident as solution lies in the core. Consequently transmission system operator would encourage the consumers to take this opportunity to lower the cost of the transmission services.

\section{3..2.2.Game for Remaining Charge Allocation:}

It is evident from Table VI that for grand coalition charges remained to be allocated are 3052.2 $\mathrm{Rs} / \mathrm{hr}$. Universally every utility follows postage stamp technique to allocate these charges among agents. Due to familiar drawbacks of postage stamp method, this effort carried out game for remaining charges. SVs of remaining charges are given in Table VIII. All three rationalities are fulfilled thus solution lies in the core. Moreover, Fig. 1 reveals that entire embedded cost distributed among players are in such a way that equitable allocations are achieved for individual player along with fairness and adequacy due to realization of core.

\subsection{IEEE 30 bus system}

Again, the game has been followed for loads in the pool market. In this case study again four players (loads) L12, L17, L21 and L30 are cooperating then the possible coalition's are 15, including single player coalition. Characteristic values attained by PRM-MVA Utility Factor method are presented in Table IX. Results obtained are presented in Table X for locational charge and remaining charge allocations which obey rationalities of game and get hold of the core.

\subsection{MVA Utility Factor Method Comparable to Shapley Approch and prospects on Larger Systems}

Shapley approach has compared with MW-Mile, Zero Counter Flow (ZCF) [28], MVA-Mile and proposed MVA Utility Factor Method (MUF) in a pool market of IEEE 6 bus system. Allocations have been made for power traded by each load. Table I and Fig. 1 are revealing equivalency of Shapley with PRM-MVA utility factor method. MW-Mile method only handles active power whereas MVA-Mile method tackles apparent power but could not predict direction of reactive power. Implementation of ZCF realizes larger allocations as counter flows are not superimposed for a line flow. Proposed MVA Utility Factor method demonstrated to be superior over existing techniques and its PRM-mode is equivalent to Shapley value approach of cooperative game because their results are quite parallel. Thus reflects prospects of MVA Utility Factor method for large systems because it is difficult to apply cooperative game on bigger systems.

Authors checked the closeness of MVA utility factor towards Shapley approach by evaluating correlation coefficients for the rationalities of game. Characteristic values shown in Tables III, VI 
and IX have been evaluated by PRM, where last row shows that PRM-MVA utility factor method obeys global rationality (3) without any conflit (section 2.2.3) and hence correlation is 1 . It is evident that MVA utility factor method always obeys break-even condition or Pareto-optimum truly (3). Theoritically maximum correlation coefficient is 1 and it should be above 0.75 . For remaining two rationalities individual as well as group the correlation coefficients have been evaluated considering cooperative game results as reference (fair). Authors found it between 0.83 to 0.99 as system grows, Table XI. Thus as the size of the system increases correlation coefficient improves. Hence better and nearer to the shapley approach. For this reason authors advocated that the proposed method is suitable for larger systems where cooperative game theory is difficult to apply.

\subsection{Comparison of Shapley Values Attained Through Different Quantification Techniques for Characteristic Values}

In this section, the sole aim of authors is to present a comparison between the transmission charge allocations (payoffs) of Shapley approach by constructing two different characteristic values using - firstly power flow tracing and secondly sensitivity factors analysis (MVA Utility Factor Method).

Table XII establishes characteristic values of coalitions in the pool market for IEEE 6 Bus System. It is evident from Table XIII that allocations obtained with characteristic values using sensitivity factors are more acceptable than characteristic values constructed using tracing flow. Table XIII reveals that difference between SV and corresponding standalone cost is more in case of sensitivity based analysis, hence more likely to be accepted by the players. That's why it is more demanding to make collaborations and not to disrupt. This encourages applicability of SV for fixed cost allocation using sensitivity factors. Thus proposed MVA utility method following sensitivity is fair and acceptable compared to other techniques of usage quantification.

\section{CONCLUSION}

MVA Utility Factor method has been proposed for cost allocation in the electricity market. Which is further used to construct characteristic value in Shapley value approach of cooperative game. Here Shapley approach has been implemented in two folds for the pool market, first- to allocate locational charges based on usage and second- to allocate remaining charges instead of postage stamp method. All solutions lie in the core of the game or near the core, hence fairest, acceptable and equitable allocations are found. Authors also demonstrated that when MVA utility Factor method solely applied for cost allocation of network results were equivalent to cost allocations achieved by Shapley approach. And nearness of two have been deduced with correlation coefficients which shows that correlation between the two methods improves as the system grows. Thus uniqueness of the work is the applicability of proposed MVA utility factor method on the large systems where cooperative game is difficult to implement as calculations become complex. Another comparision made which advocates to use MP mode of quantification of line usage as compared to tracing flow.

\section{REFERENCES}

[1] Static. W. Yu, A. K. David and Y. K. Wong, "The Use of Game Theory in Transmission Embedded Cost Allocation," Proceedings of the 5th International Conference on Advances in Power System Control, Operation and Management, APSCOM 2000, Hong Kong, October 2000. 
[2] Paul M. Sotkiewicz and J. Mario Vignolo, "Allocation of Fixed Costs in Distribution Networks With Distributed Generation," IEEE Transaction on Power Systems, Vol. 21, No. 2, pp. 639-652, May 2006.

[3] Bialek J., "Tracing the Flow of Electricity," IEEE Proceedings on Generation, Transmission and Distribution, Vol. 143, No. 4, pp. 313-320, July 1996.

[4] J. W. Bialek and P.A.Kattuman, "Proportional Sharing Assumption in Tracing Methodology," Proc. Inst. Elect. Eng., Vol. 151, No. 4, pp. 526-532, July 2004.

[5] F. J. Rubio-Oderiz and Ignacio J. Perez-Arriaga, "Marginal Pricing of Transmission Services: A Comparative Analysis of Network Cost Allocation Methods," IEEE Transaction on Power System. Vol. 15, No.1, pp. 448-454, Feb. 2000.

[6] H.Rudnick, R. Palma and J.E.Fernandez, "Marginal Pricing and Supplement Cost Allocation in Transmission Open Access", IEEE Transactions on Power System, Vol. 10, No. 2, pp. 1125-1132, May 1995.

[7] F.D. Galiana, A.J. Conejo and H.A. Gil, "Transmission Network Cost Allocation Based on Equivalent Bilateral Exchanges,” IEEE Trans. Power Syst., Vol. 18, No. 4, pp. 1425-1431, 2003.

[8] Antonio J. Conejo, Francisco D. Galiana and IvanaKockar, "Z-Bus Loss Allocation," IEEE Transactions on Power Systems, Vol. 16, No. 1, pp. 105-110, February 2001.

[9] A.J. Conejo, J. Contreras, D.A. Lima and A. Padilha-Feltrin, "Z-bus Transmission Network Cost Allocation," IEEE Trans. Power Syst. Vol. 22, No. 1, pp. 342-349, 2007.

[10] Jaun M. Zolezzi and H. Rudnick, "Transmission Cost Allocation by Cooperative Games and Coalition Formation," IEEE Transaction on Power Systems. Vol. 17, No. 4, pp. 1008-1015, Nov. 2002.

[11] Max Junqueira, Luiz Carlos da Costa, Jr., Luiz Augusto Barroso, Gerson C. Oliveira, Luiz Mauricio Thome and Mario Veiga Pereira, "An Aumann-Shapley Approach to Allocate Transmission Service Cost Among Network Users in Electricity Markets," IEEE Transactions on Power Systems, Vol. 22, No. 4, pp. 1532-1546, November 2007.

[12] G.C. Stamtsis and I. Erlich, "Use of Cooperative Game Theory in Power System Fixed Cost Allocation,” IEE Proc.-Gener. Transm. Distrib., Vol. 151, No. 3, pp. 401-406, May 2004.

[13] D. Shrimohammadi, Paul R. Gribik, Eric T.K. Law, James H. Malinowski, and Richard E.O’Donnell, "Evaluation of Transmission Network Capacity Use for Wheeling Transactions", Pacific Gas and Electric Company San Francisco, California, IEEE Trans Power Syst 4(1989), pp 1405-1413.

[14] Ching-Tzong Su and Ji-HorngLiaw, "Power Wheeling Pricing Using Power Tracing and MVA-KM Method," IEEE, 2001, http://ieeexplore.ieee.org/stamp/stamp.jsp? arnumber=00964570.

[15] RohitBhakar, V. S. Sriram, Narayana Prasad Padhy and Hari Om Gupta, "Probabilistic Game Approaches for Network Cost Allocation," IEEE Transactions on Power Systems, Vol. 25, No. 1, pp. 51-58, February 2010.

[16] Thesis by GeorgiosStamtsis, "Power transmission Cost Calculation in Deregulated Electricity Market," December 2003, http://duepublico.uni-duisburg-essen.de/servlets/DerivateServlet/ Derivate $-5501 /$ stamtsisdiss. pdf.

[17] Y.Tsukamoto, and I.Iyoda, "Allocation of Fixed Transmission Cost to Wheeling Transactions by Cooperative Game Theory,” IEEE Trans. Power Syst., Vol. 11, No. 2, pp. 620-629, 1996.

[18] X. Tan and T. T. Lie, "Application of the Shapley Value on Transmission Cost Allocation in the Competitive Power Market Environment,” Proc. Inst. Elect. Eng., Gen., Transm.,Distrib., vol. 149, no. 1, pp. 15-20, January 2002.

[19] C. W. Yu, A. K. David, C. T. Tse and C. Y. Chung, "Capacity-Use and Reliability Based Transmission Embedded Cost Allocation with Temporal Considerations," Int. J. Elect. Power Energy Syst., vol. 25, pp. 201-208, 2003.

[20] DeqiangGan, Jianquan Wang and Donald V. Bourcier, "An Auction Game Model for Pool-Based Electricity Markets,” Electrical Power and Energy Systems, Vol. 27, pp. 480-487, 2005.

[21] M. Junqueira, G.C. Oliveira, L.M. Thomé, S. Granville, L.A. Barroso and M.V. Pereira, "Transmission Cost Allocation Schemes for Electricity Markets: A Game-Theoretic Approach," Symposium of Specialists in Electric Operational and Expansion Planning, pp. 1-10, May - 21st to 25th, 2006, Brazil,.

[22] Max Junqueira, Luiz Carlos da Costa, Jr., Luiz Augusto Barroso, Gerson C. Oliveira, Luiz Mauricio Thome and Mario Veiga Pereira, "An Aumann-Shapley Approach to Allocate Transmission Service 
Cost Among Network Users in Electricity Markets," IEEE Transactions on Power Systems, Vol. 22, No. 4, November 2007.

[23] RohitBhakar, V.S. Sriram, Narayana Prasad Padhy and H.O. Gupta, "Network Embedded Cost Allocation: A Game-Theoretic Approach” XXXII National Systems Conference, NSC 2008, pp. 395399, December 17-19, 2008.

[24] Sameer Mehra and Ravi Patni, "Analysis of POC Charging Method and Regional Postage Stamp Method for Cost Allocation For Transmission Line Usage," Vol. 3, No. 6, June 2011, http://www.ijest.info /docs/IJEST11-03-06-233.pdf.

[25] J.D.Molina and H.Rudnick, "Transmission Expansion Investment: Cooperative or Non-Cooperative Game?," Power and Energy Society General Meeting, IEEE, Minneapolis, pp. 1-7, 25-29 July 2010.

[26] PierraeDehez, "Fair Division of Fixed Costs Defines the Shapley Value," September 2007, Electronic copy available at: http://ssrn.com/abstract=970910.

[27] S. M. H. Nabavi, S. Hajforoosh, S. Hajforosh, N. A. Hosseinipoor, "Using Tracing Method for Calculation and Allocation of Reactive Power Cost," International Journal of Computer Applications, Volume 13, No.2, January 2011.

[28] Jiuping Pan, YonaelTeklu, SaifurRahman and Koda Jun, "Review of Usage-Based Transmission Cost Allocation Methods under Open Access," IEEE Transactions on Power Systems, Vol. 15, No. 4, pp. 1218-1224, November 2000.

[29] Tarun Tailor, Ganga Agnihotri and Anuprita Sandeep Mishra, "Usage Based Cost Allocation Technique for EHV Networks Using Non-linear Utility Factors," Electrical and Electronics Engineering, Vol. 2, No. 2, pp. 61-75, May 2013.

Table I

IEEE 6-Bus System: Comparison of Cost Allocation by MVA Utility Method with Different Methodologies Under 100\% Base Case Loading

\begin{tabular}{|c|c|c|c|c|c|c|c|}
\hline Load No. & $\begin{array}{l}\text { MW-Mile } \\
\text { (Rs./hr) }\end{array}$ & $\begin{array}{c}\mathrm{ZCF} \\
\text { (Rs./hr) }\end{array}$ & $\begin{array}{l}\text { MVA-Mile } \\
\text { (Rs./hr) }\end{array}$ & $\begin{array}{l}\text { I- Mile } \\
\text { (Rs./hr) }\end{array}$ & $\begin{array}{c}\text { MVA UF } \\
\text { Method } \\
\text { (PRM) (Rs./hr) }\end{array}$ & $\begin{array}{c}\text { MVA UF } \\
\text { Method } \\
\text { (FRM) } \\
\text { (Rs./hr) }\end{array}$ & $\begin{array}{l}\text { Shapely } \\
\text { Value }\end{array}$ \\
\hline L4 & 203.4063 & 307.6034 & 316.9967 & 100.47 & 206.1199 & 358.3 & 186.5689 \\
\hline L5 & 480.5447 & 531.4648 & 456.5107 & -13.13 & 367.4848 & 2658.9 & 333.5845 \\
\hline L6 & 443.2936 & 530.5985 & 308.2618 & 2.04 & 244.2181 & 1167.8 & 297.6696 \\
\hline Cost Allocated & 1127.2 & 1369.7 & 1081.8 & 462.67 & 817.8229 & 4184.9 & 817.8230 \\
\hline $\mathrm{RC}$ & 3057.7 & 2815.2 & 3103.1 & 3722.23 & 3367.0771 & 0 & 3367.0771 \\
\hline Embedded Cost (in \%) & $26.93 \% \%$ & $32.72 \%$ & $25.85 \%$ & $11.05 \%$ & $19.5 \%$ & $100 \%$ & $19.5 \%$ \\
\hline
\end{tabular}

Table II

Players of 6 Bus Pool Market

\begin{tabular}{ccc}
\hline \hline Player & Bus & $\begin{array}{c}\text { Demand } \\
\text { (PU) }\end{array}$ \\
\hline L4 & 4 & 0.7 \\
L5 & 5 & 0.7 \\
L6 & 6 & 0.7 \\
\hline \hline
\end{tabular}


Electrical and Electronics Engineering: An International Journal (ELELIJ) Vol 3, No 2, May 2014

Table III

Characteristics Value of Different Coalitions in the Pool Market for IEEE 6 Bus System

\begin{tabular}{ccccccc}
\hline \hline $\begin{array}{c}\text { Sr. } \\
\text { No. }\end{array}$ & $\begin{array}{c}\text { Coalition } \\
(S)\end{array}$ & $\begin{array}{c}\text { L4 } \\
{[\text { Rs./hr] }}\end{array}$ & $\begin{array}{c}\text { L5 } \\
{[\mathrm{Rs} . / \mathrm{hr}]}\end{array}$ & $\begin{array}{c}\text { L6 } \\
{[\mathrm{Rs} . / \mathrm{hr}]}\end{array}$ & $\begin{array}{c}\text { Loc. Charge } \\
\text { Char. value } \\
v(S)[\mathrm{Rs} . / \mathrm{hr}]\end{array}$ & $\begin{array}{c}\text { Rem. Charge } \\
\text { Char. value } \\
{[\mathrm{Rs} . / \mathrm{hr}]}\end{array}$ \\
\hline 1 & L4 & 213.8819 & 0 & 0 & 213.8819 & 3971.0 \\
2 & L5 & 0 & 355.7332 & 0 & 355.7332 & 3829.2 \\
3 & L6 & 0 & 0 & 362.0144 & 362.0144 & 3822.9 \\
4 & L4L5 & 224.3514 & 323.0787 & 0 & 547.4301 & 3637.5 \\
5 & L4L6 & 206.6749 & 0 & 262.6441 & 469.3190 & 3715.6 \\
6 & L5L6 & 0 & 364.2379 & 257.2611 & 621.4990 & 3563.4 \\
7 & L4L5L6 & 206.1199 & 367.4848 & 244.2181 & 817.8229 & 3367.1 \\
\hline \hline
\end{tabular}

Table IV

Acceptability of Shapley Value: Initial and Final Usage Cost for Each Player in 6 Bus Pool Market

\begin{tabular}{llll}
\hline \hline & $\begin{array}{l}\text { Standalone } \\
\text { Player. }\end{array}$ & $\begin{array}{l}\text { Shapley } \\
\text { Value }\end{array}$ & Savings \\
& $v(i)[\mathrm{Rs} . / \mathrm{hr}]$ & $\begin{array}{l}\emptyset_{i}(v)=x_{i} \\
{[\mathrm{Rs} . / \mathrm{hr}]}\end{array}$ & \\
& {$[\mathrm{Rs} . / \mathrm{hr}]$} \\
\hline L4 & 213.8819 & 186.5689 & 27.313 \\
L5 & 355.7332 & 333.5845 & 22.1487 \\
L6 & 362.0144 & 297.6696 & 64.3448 \\
Total & & 817.8230 & 113.8065 \\
\hline \hline
\end{tabular}

Table V

Shapley Value Attained by Cooperative Gaming of Generators for 6 Bus Pool Market

\begin{tabular}{lll}
\hline \hline Agent & $\begin{array}{l}\text { Standalone } \\
\text { condition }\end{array}$ & $\begin{array}{l}\text { Shapley } \\
\text { Value }\end{array}$ \\
\hline G1 & 187.6386 & 12.5043 \\
G2 & 140.0531 & -28.0488 \\
G3 & 264.9595 & 40.5133 \\
Total & & 24.9688 \\
\hline \hline
\end{tabular}

Table VI

Characteristic Values of Different Coalitions for 14 Bus Pool Market

\begin{tabular}{cccccccc}
\hline \hline $\begin{array}{c}\text { Sr. } \\
\text { No }\end{array}$ & $\begin{array}{c}\text { Coalition } \\
(S)\end{array}$ & $\begin{array}{c}\text { L4 } \\
{[\mathrm{Rs} . / \mathrm{hr}]}\end{array}$ & $\begin{array}{c}\text { L9 } \\
{[\mathrm{Rs} . / \mathrm{hr}]}\end{array}$ & $\begin{array}{c}\text { L12 } \\
{[\mathrm{Rs} . / \mathrm{hr}]}\end{array}$ & $\begin{array}{c}\text { L14 } \\
{[\mathrm{Rs} . / \mathrm{hr}]}\end{array}$ & $\begin{array}{c}\text { Loc. Charge } \\
\text { Char. value } \\
v_{L}(S)[\mathrm{Rs} . / \mathrm{hr}]\end{array}$ & $\begin{array}{c}\text { Rem. Charge } \\
\text { Char. value } \\
v_{R}(S)[\mathrm{Rs} . / \mathrm{hr}]\end{array}$ \\
\hline 1 & L4 & 107.6836 & 0 & 0 & 0 & 107.6836 & 3613.4 \\
2 & L9 & 0 & 370.4680 & 0 & 0 & 370.4680 & 3350.6 \\
3 & L12 & 0 & 0 & 91.8526 & 0 & 91.8526 & 3629.2 \\
4 & L14 & 0 & 0 & 0 & 242.6674 & 242.6674 & 3478.4 \\
5 & L4L9 & 90.5569 & 364.0283 & 0 & 0 & 454.5853 & 3023.8 \\
6 & L4L12 & 76.1095 & 0 & 78.6053 & 0 & 154.7148 & 3566.4 \\
7 & L4L14 & 85.4387 & 0 & 0 & 241.6145 & 327.0532 & 3394.0 \\
8 & L9L12 & 0 & 363.9333 & 52.1697 & 0 & 416.1029 & 3305.0 \\
9 & L9L14 & 0 & 309.5294 & 0 & 233.1173 & 542.6467 & 3178.5 \\
10 & L12L14 & 0 & 0 & 61.6429 & 229.1456 & 290.7885 & 3430.3 \\
11 & L4L9L12 & 88.9197 & 359.8500 & 52.0202 & 0 & 500.7899 & 3220.3 \\
12 & L4L9L14 & 83.4951 & 308.4299 & 0 & 232.3681 & 624.2932 & 3096.8 \\
13 & L4L12L14 & 83.9156 & 0 & 61.3832 & 228.2530 & 373.5519 & 3347.5 \\
14 & L9L12L14 & 0 & 313.5178 & 40.0642 & 235.1032 & 588.6851 & 3132.4 \\
15 & L4L9L12L14 & 83.3074 & 311.4956 & 39.8837 & 234.1764 & 668.8631 & 3052.2 \\
\hline \hline
\end{tabular}


Electrical and Electronics Engineering: An International Journal (ELELIJ) Vol 3, No 2, May 2014

Table VII

Applicability of Shapley Approach for Locational Charge Allocation in 14 Bus Pool Market

\begin{tabular}{|c|c|c|c|}
\hline Player & $\begin{array}{l}\text { Standalone } \\
\text { Cost } \\
v_{L}(i) \\
\text { [Rs./hr] }\end{array}$ & $\begin{array}{l}\text { Shapley Value } \\
\emptyset_{i}(v)=x_{i} \\
{[\text { Rs./hr }]}\end{array}$ & $\begin{array}{l}\text { Savings } \\
\text { [Rs./hr] }\end{array}$ \\
\hline L4 & 107.6836 & 87.0039 & 20.6797 \\
\hline L9 & 370.4680 & 325.8067 & 44.6613 \\
\hline L12 & 91.8526 & 57.3997 & 34.4529 \\
\hline L14 & 242.6674 & 198.6528 & 44.0146 \\
\hline Total & & 668.8631 & 143.8085 \\
\hline
\end{tabular}

Table VIII

Shapley Approach for Remaining Charge Allocation to IEEE 14 Bus System

\begin{tabular}{|c|c|c|c|}
\hline Player & $\begin{array}{l}\text { Standalone } \\
\text { Cost } \\
v_{R}(i) \\
{[\mathrm{Rs} . / \mathrm{hr}]}\end{array}$ & $\begin{array}{l}\text { Shapley } \\
\text { Value } \\
\emptyset_{i}(v)=x_{i} \\
{[\mathrm{Rs} . / \mathrm{hr}]}\end{array}$ & $\begin{array}{l}\text { Savings } \\
{[\mathrm{Rs} . / \mathrm{hr}]}\end{array}$ \\
\hline 1 & $\mathrm{~L} 4$ & 3613.4 & 823.0333 \\
\hline 2 & L9 & 3350.6 & 584.2500 \\
\hline 3 & L12 & 3629.2 & 893.0833 \\
\hline 4 & L14 & 3478.4 & 751.8333 \\
\hline Total & & & 3052.2 \\
\hline
\end{tabular}

Table IX

Characteristic Values for Locational Charge Allocation and Remaining Charge Allocation in IEEE 30 Bus System

\begin{tabular}{cccccccc}
\hline \hline Sr. No & $\begin{array}{c}\text { Coalition } \\
(S)\end{array}$ & $\begin{array}{c}\text { L12 } \\
{[\mathrm{Rs} / \mathrm{hr}]}\end{array}$ & $\begin{array}{c}\text { L17 } \\
{[\mathrm{Rs} . / \mathrm{hr}]}\end{array}$ & $\begin{array}{c}\text { L21 } \\
{[\mathrm{Rs} . / \mathrm{hr}]}\end{array}$ & $\begin{array}{c}\text { L30 } \\
{[\mathrm{Rs} . / \mathrm{hr}]}\end{array}$ & $\begin{array}{c}\text { Loc. Charge } \\
\text { Char. value } \\
v(S)[\mathrm{Rs} / \mathrm{hr}]\end{array}$ & $\begin{array}{c}\text { Rem. Charge } \\
\text { Char. value } \\
{[\text { Rs./hr }]}\end{array}$ \\
\hline 1 & L12 & 1701.8 & 0 & 0 & 0 & 1701.8 & 93346 \\
2 & L17 & 0 & 1651.9 & 0 & 0 & 1651.9 & 93396 \\
3 & L21 & 0 & 0 & 3823.0 & 0 & 3823.0 & 91225 \\
4 & L30 & 0 & 0 & 0 & 5640.1 & 5640.1 & 119660 \\
5 & L12L17 & 1561.9 & 1423.5 & 0 & 0 & 2985.4 & 92063 \\
6 & L12L21 & 1531.5 & 0 & 3221.9 & 0 & 4753.3 & 90295 \\
7 & L12L30 & 1423.7 & 0 & 0 & 5197.7 & 6621.4 & 118680 \\
8 & L17L21 & 0 & 1568.7 & 3536.5 & 0 & 5105.3 & 89943 \\
9 & L17L30 & 0 & 1248.4 & 0 & 5559.5 & 6807.9 & 118490 \\
10 & L21L30 & 0 & 0 & 3354.7 & 5273.9 & 8628.6 & 116670 \\
11 & L12L17L21 & 1156.3 & 1360.6 & 3053.4 & 0 & 5570.3 & 89478 \\
12 & L12L17L30 & 1.4563 & 1056.4 & 0 & 5354.1 & 7866.8 & 117430 \\
13 & L12L21L30 & 1045.1 & 0 & 3152.2 & 5247.5 & 9444.9 & 115860 \\
14 & L17L21130 & 0 & 1418.9 & 3254.7 & 5029.0 & 9702.7 & 115600 \\
15 & L12L17L21L30 & 905.2 & 1240.9 & 2774.8 & 4987.0 & 9908.0 & 118362 \\
\hline \hline
\end{tabular}


Electrical and Electronics Engineering: An International Journal (ELELIJ) Vol 3, No 2, May 2014

Table X

Shapley Values for Locational and Remaining Charge Allocations in 30 Bus System

\begin{tabular}{cccc}
\hline \hline Player & $\begin{array}{c}\text { Shapley Value } \\
\text { in Loc. Charge } \\
\text { allocation } \\
\emptyset_{i}\left(v_{L}\right)=x_{i} \\
{[\text { Rs./hr] }}\end{array}$ & $\begin{array}{c}\text { Shapley Value } \\
\text { in Rem.Charge } \\
\text { allocation } \\
\emptyset_{i}\left(v_{R}\right)=x_{R i} \\
{[\text { Rs./hr }]}\end{array}$ & Total \\
\hline L12 & 942.2167 & 23562 & 24504.267 \\
L17 & 1101.3 & 23402 & 24503.3 \\
L21 & 2949.1 & 21557 & 24506.1 \\
L30 & 4915.4 & 49841 & 54756.4 \\
Total & 9908.0 & 118362 & 128270 \\
\hline \hline
\end{tabular}

Table XI

Correlation coefficients: Closeness of MVAUF Method Allocations towards Rationalities of Cooperative game

\begin{tabular}{cccc}
\hline \hline \multirow{2}{*}{ Size of System } & Individual & Group & Global \\
& & & \\
\hline 6 Bus & 0.83 & 0.83 & 1 \\
14 Bus & 0.98 & 0.98 & 1 \\
30 Bus & 0.99 & 0.99 & 1 \\
\hline \hline
\end{tabular}

Table XII

Characteristic Value of Coalition in the Pool Market for IEEE 6 Bus System

\begin{tabular}{ccc}
\hline \hline $\begin{array}{r}\text { Coalition } \\
(S)\end{array}$ & $\begin{array}{c}\text { Sensitivity Based } \\
\text { Charac. Value } \\
\text { [Rs./hr] }\end{array}$ & $\begin{array}{c}\text { Tracing Flow Based } \\
\text { Charac. Value } \\
\text { [Rs./hr] }\end{array}$ \\
\hline L4 & 213.8819 & 161.107 \\
L5 & 355.7332 & 374.46 \\
L6 & 362.0144 & 229.04 \\
L4L5 & 547.4301 & 547.069 \\
L4L6 & 469.3190 & 396.05 \\
L5L6 & 621.4990 & 614.79 \\
L4L5L6 & 817.8229 & 759.08 \\
\hline \hline
\end{tabular}

Table XIII

Comparison of cost Allocations Using Different Characteristic Values by Shapley value

\begin{tabular}{ccccc}
\hline \hline \multirow{2}{*}{ Agent } & \multicolumn{2}{c}{ Stand Alone } & \multicolumn{2}{c}{ Shapley Value } \\
\cline { 2 - 5 } & Sensitivity & Tracing & Sensitivity & Tracing \\
& Based & Flow Based & Based & Flow Based \\
\hline L4 & 213.8819 & 161.107 & 186.5689 & 158.402 \\
L5 & 355.7332 & 374.46 & 333.5845 & 374.45 \\
L6 & 362.0144 & 229.04 & 297.6696 & 226.23 \\
& Total & & 817.8230 & 759.082 \\
\hline \hline
\end{tabular}




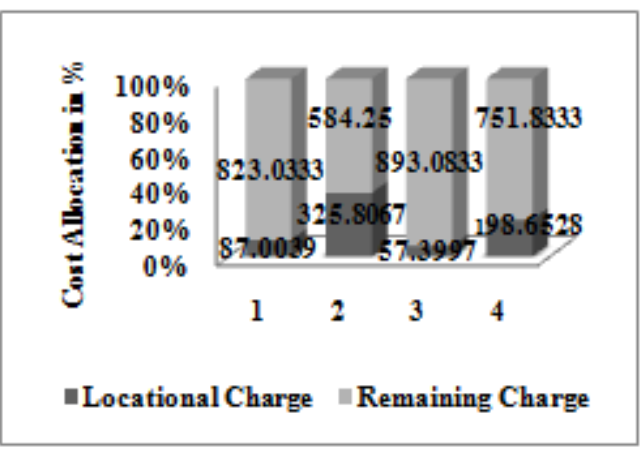

Fig. 1: Allocation of locational and remaining through gaming for IEEE 14 bus system

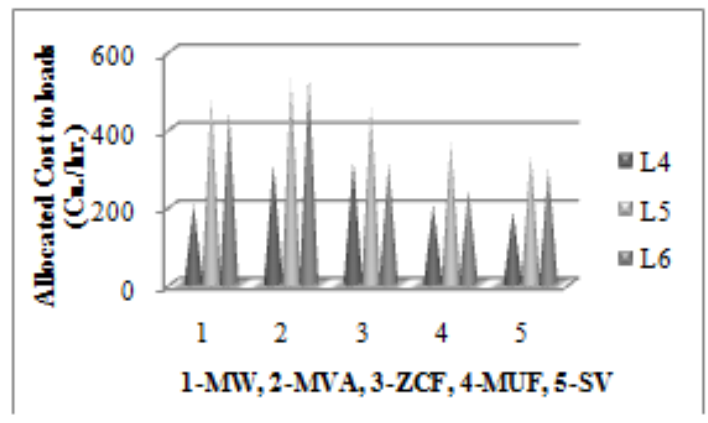

Fig. 2: Comparison of existing techniques with proposed MVA utility Factor method and SV for IEEE 6 bus system 